\title{
Polymorphisms in the SULF1 gene are associated with early age of onset and survival of ovarian cancer
}

\author{
Chan H Han', Yu-Jing Huang ${ }^{1}$, Karen H Lu², Zhensheng Liu', Gordon B Mills³ ${ }^{3}$ Qingyi Wei', Li-E Wang ${ }^{1 *}$
}

\begin{abstract}
Background: SULF1 (sulfatase 1) selectively removes the 6-O-sulphate group from heparan sulfate, changing the binding sites for extracellular growth factors. SULF1 expression has been reported to be decreased in various cancers, including ovarian cancer. We hypothesized that single nucleotide polymorphisms (SNPS) of SULF1 would impact clinicopathologic characteristics.
\end{abstract}

Methods: We genotyped five common (minor allele frequency $>0.05$ ) regulatory SNPs with predicted functionalities (rs2623047 G>A, rs13264163 A>G, rs6990375 G>A, rs3802278 G>A, and rs3087714 C>T) in 168 patients with primary epithelial ovarian cancer, using the polymerase chain reaction-restriction fragment length polymorphism method.

Results: We found that rs $2623047 \mathrm{G}>\mathrm{A}$ was significantly associated with an early age of onset of ovarian cancer in the $\mathrm{G}$ allele dose-response manner $\left(P=0.027 ; P_{\text {trend }}=0.007\right)$ and that $\mathrm{rs} 2623047 \mathrm{GG} / \mathrm{GA}$ genotypes were associated with longer progression-free survival; rs6990375 G>A was also associated with the early age of onset in the A allele dose-response manner $\left(P=0.013 ; P_{\text {trend }}=0.009\right)$. The significant differences in age of disease onset persisted among carriers of haplotypes of rs2623047 and rs6990375 ( $\left.P=0.014 ; P_{\text {trend }}=0.004\right)$. In luciferase reporter gene assays, rs $2623047 \mathrm{G}$ allele showed a slightly higher promoter activity than the A allele in the SKOV3 tumorigenic cell line.

Conclusions: These findings suggest that genetic variations in SULF1 may play a role in ovarian cancer onset and prognosis. Further studies with large sample sizes and of the mechanistic relevance of SULF1 SNPS are warranted.

\section{Background}

SULF1 is a newly identified human sulfatase with aryl-sulfatase activities, which can influence the sulfation status and biological function of heparan sulfate proteoglycans (HSPGs) [1]. This heparan sulfate 6-O-endosulfatase selectively removes 6-O-sulphate group and alters the binding sites of signaling molecules [2]. HSPGs are protein-conjugated forms of heparin sulfate glycosaminoglycans (HSGAGs) in vivo and major constituents of the extracellular matrix (ECM). HSGAGs in the ECM interact with many signaling molecules, regulate their biological activities, and express profound effects on cell growth kinetics and metastasis of tumor cells [3,4]. By interacting

\footnotetext{
* Correspondence: Iwang@mdanderson.org

'Department of Epidemiology, The University of Texas M. D. Anderson

Cancer Center, Houston, TX 77030, USA

Full list of author information is available at the end of the article
}

with numerous mediators including growth factors, cytokines, chemokines, and adhesion molecules, HSGAGs are involved in a wide array of biological processes, such as homeostasis, anticoagulation, angiogenesis, embryogenesis, as well as in oncogenic transformation of normal cells to tumor cells [5-10].

The correlation between SULF1 and cancer risk has mainly been studied in terms of gene expression. SULF1 expression is decreased in multiple malignant lineages, and its re-expression is known to be associated with decreased signaling of heparin-binding growth factors, cell proliferation, and the invasiveness of cancer cells [11-14]. In ovarian cancer, decreased expression of SULF1 and its correlation with decreased sensitivity to cisplatin (a standard chemotherapeutic agent) were also reported $[12,15]$.

\section{() Biomed Central}

(c) 2011 Han et al; licensee BioMed Central Ltd. This is an Open Access article distributed under the terms of the Creative Commons Attribution License (http://creativecommons.org/licenses/by/2.0), which permits unrestricted use, distribution, and reproduction in any medium, provided the original work is properly cited. 
Loss of heterozygosity or hypermethylation of the promoter region has been suggested as potential mechanisms for SULF1 down-regulation in ovarian cancer [14]. Besides, genetic variation has been implicated in altered gene expression, especially those regulatory polymorphisms that are located in promoter regions [16,17]. However, genetic variation in SULF1 has not been explored in ovarian cancer. In this study, we genotyped five common (i.e. minor allele frequency $>0.05$ ) single nucleotide polymorphisms (SNPs) with predicted functionalities (rs2623047 G>A, rs13264163 A>G, rs6990375 G>A, rs3802278 G>A, and rs3087714 C>T ) to evaluate associations between these potentially functional SULF1 SNPs and clinical outcomes in 168 ovarian cancer patients whose DNA and clinic variables were available, and investigated whether the promoter activity of rs2623047 A>G may be underlying the functional significance.

\section{Methods}

\section{Study Population}

The study population and data collection were described previously [18]. Briefly, the 168 patients were registered at The University of Texas M. D. Anderson Cancer Center between 2000 and 2007 and diagnosed with histopathologically confirmed primary epithelial ovarian cancer. Patients had been treated with chemotherapy, a combination of platinum (carboplatin, cisplatin) and taxanes (taxol, docetaxel) following optimal debulking or cyto-reductive surgery. Available demographic characteristics included age at diagnosis and race, and clinicopathologic characteristics including tumor stage, cell type and grade, optimality of the primary debulking operation, chemotherapy regimen, number of chemotherapies, disease recurrence, and response of tumors to chemotherapy. The optimal debulking or cyto-reductive surgery is defined as the largest residual tumor nodule measuring $1 \mathrm{~cm}$ or less, according to the Gynecologic Oncology Group [19]. The response evaluation criteria in solid tumors (RECIST) [20] were used to define the response of tumors to treatment.

Overall survival (OS) and progression-free survival (PFS) were calculated as the date of disease diagnosis to the date of death or last contact or the date of recurrence or progression, accordingly. Disease recurrence was defined as the reappearance of any lesion that had previously disappeared or the appearance of a new lesion that was histopathologically confirmed by a biopsy. Information about the date of last contact and status of patients at the last contact was obtained from the M. D. Anderson Tumor Registry and Social Security Death Index, when this information was missing from the medical records. This study was approved by the $\mathrm{M}$. D. Anderson Institutional Review Board.

\section{SNP Selection and Genotyping}

Using SULF1 gene position from International HapMap project http://hapmap.ncbi.nlm.nih.gov/cgi-perl/gbrowse/ hapmap28_B36/\#search with the extension of $2 \mathrm{~kb}$ at both sides to cover near gene regions (chr8:70539427.. 70737701), we found that five of 355 SNPs were common in HapMap Caucasian population with one of following predicted functionalities at the SNP Function Prediction website http://snpinfo.niehs.nih.gov/snpfunc.htm: (1) affecting transcription factor binding sites (TFBS) activity in the putative promoter region, (2) affecting splicing activity, or (3) affecting the microRNA binding sites activity. Therefore, we genotyped all of these five SNPs: rs2623047 G>A, rs13264163 A>G, rs6990375 G>A, rs3802278 G>A, and rs3087714 C>T.

The genotyping was performed by the polymerase chain reaction-restriction fragment length polymorphism method (PCR-RFLP) using genomic DNA. Table 1 shows the primers and PCR information for each SNP. The PCR conditions consisted of an initial melting step of $95^{\circ}$ $\mathrm{C}$ for $5 \mathrm{~min}$, followed by 35 cycles of denaturation $\left(95^{\circ} \mathrm{C}\right.$ for 30 seconds), annealing $\left(52-55^{\circ} \mathrm{C}\right.$ for $45 \mathrm{sec}$ according to SNPs), and extension $\left(72^{\circ} \mathrm{C}\right.$ for $\left.1 \mathrm{~min}\right)$, and a final extension step of $72^{\circ} \mathrm{C}$ for $10 \mathrm{~min}$. The digested products were checked on a $3 \%$ MetaPhor agarose gel containing ethidium bromide. The gene structure, SNP location, predicted functionality of SNPs, and electrophoresis gel pictures are shown in Figure 1A. The genotypes were double-checked by two people for quality control, and any uncertain results were repeated to reach a $100 \%$ concordance. Genotyping of $10 \%$ of samples were randomly performed twice, and no discrepancy was observed.

\section{Construction of Reporter Plasmids}

Reporter constructs were prepared for rs2623047 G>A by amplifying $1803 \mathrm{bp}$ of the SULF1 promoter region (from -1784 to +18 relative to the transcription start site) with either rs2623047 G or A allele by using a pair of primers 5'-AAGAGCTCTTGGGAATGCCTCATAGACAG-3' (forward) and 5'-AAGCTAGCGGTCTGAGAACTCCCAGTCAA-3' (reverse). SacI and NheI restriction enzymes (New England BioLabs, Beverly, MA) were used to cleave the amplicons, and the pGL4 vector (Promega, Madison, WI) and T4 DNA ligase (New England BioLabs) were used for ligation.

\section{Transient Transfection and Luciferase Reporter Gene Assay}

The ovarian cancer cell lines OVCA429 and SKOV-3 were cultured in 1x McCoy's 5A modified medium and minimum essential medium, and the human cervical cancer cell line HeLa was cultured in Dulbecco's modified Eagle's medium, supplemented with $10 \%$ fetal bovine serum (Sigma-Aldrich, MO) at $37^{\circ} \mathrm{C}$ with $5 \%$ 
Table 1 Primers and PCR conditions for genotyping the five SNPs

\begin{tabular}{|c|c|c|c|c|c|c|}
\hline rs number & & Primers & $\begin{array}{l}\text { Annealing } \\
\text { Temperature }\left({ }^{\circ} \mathrm{C}\right)\end{array}$ & $\begin{array}{l}\text { PCR products } \\
\text { (bp) }\end{array}$ & Enzyme & $\begin{array}{l}\text { Digested PCR } \\
\text { products (bp) }\end{array}$ \\
\hline rs2623047 & $\mathrm{FP}$ & 5'-TGT GGC AAA CAG TGA AGA GC-3 & 52 & 245 & BstNl & GG:159/86 \\
\hline \multirow[t]{2}{*}{$\mathrm{G}>\mathrm{A}$} & $\mathrm{RP}$ & $5^{\prime}-\mathrm{CAG}$ CAA GAC GTT TTC CCT TC-3' & & & & GA:245/159/86 \\
\hline & & & & & & AA:245 \\
\hline rs13264163 & FP & 5'-TGG CAA TTT TGC TCT TाT CC-3' & 55 & 181 & Nspl & AA:100/81 \\
\hline \multirow[t]{2}{*}{$A>G$} & $\mathrm{RP}$ & 5'-TGA CAT AGA GTG CCC AGG TG-3 & & & & GA:181/100/81 \\
\hline & & & & & & GG:181 G \\
\hline rs6990375 & FP & $5^{\prime}-C C G$ CAG AAC ACC GAA GTA AT-3' & 55 & 227 & Hhal & GG:128/99 \\
\hline \multirow[t]{2}{*}{$\mathrm{G}>\mathrm{A}$} & $\mathrm{RP}$ & 5'-CCA GGG TAG CTT GGA ATG TT-3 & & & & GA:227/128/99 \\
\hline & & & & & & AA:227 \\
\hline rs3802278 & FP & 5'-CTG GAA ACC GAT TTC AGT GG-3' & 55 & 227 & Cac8l & GG:151/76 \\
\hline \multirow[t]{2}{*}{$\mathrm{G}>\mathrm{A}$} & $\mathrm{RP}$ & 5'-CCC GCT ATG CTG GAA TTA CT-3 & & & & GA:227/151/76 \\
\hline & & & & & & AA:227 \\
\hline rs3087714 & $\mathrm{FP}$ & $5^{\prime}-\pi \mathrm{C}$ CTG AAG CCA GAA TTG TTC-3' & 55 & 150 & CviQl & CC:150 \\
\hline \multirow[t]{2}{*}{$C>T$} & $\mathrm{RP}$ & 5'- TAT CAT CGG TGG GAT GAC AG-3' & & & & $C T: 150 / 101 / 49$ \\
\hline & & & & & & ТТ:101/49 \\
\hline
\end{tabular}

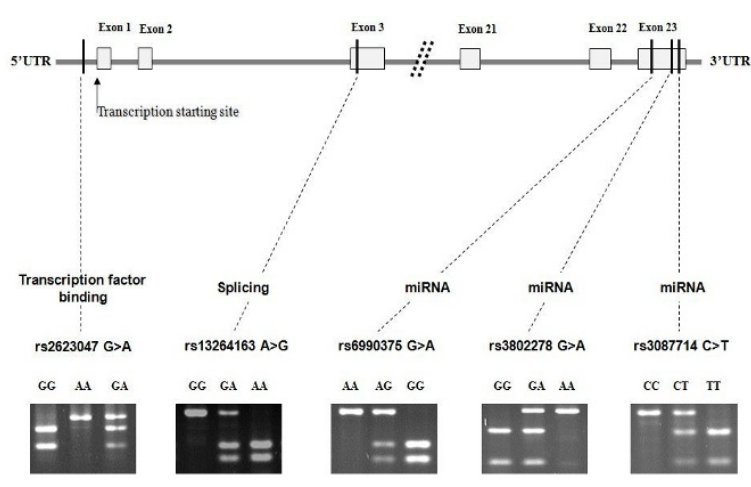

(A)

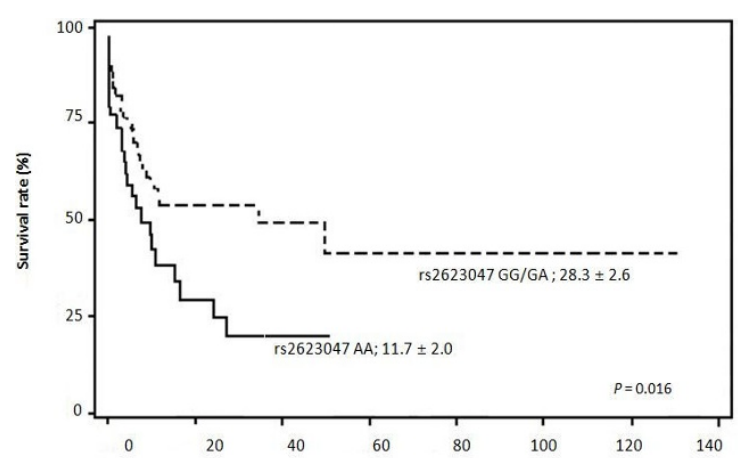

(C)

Progression free survival ( months)

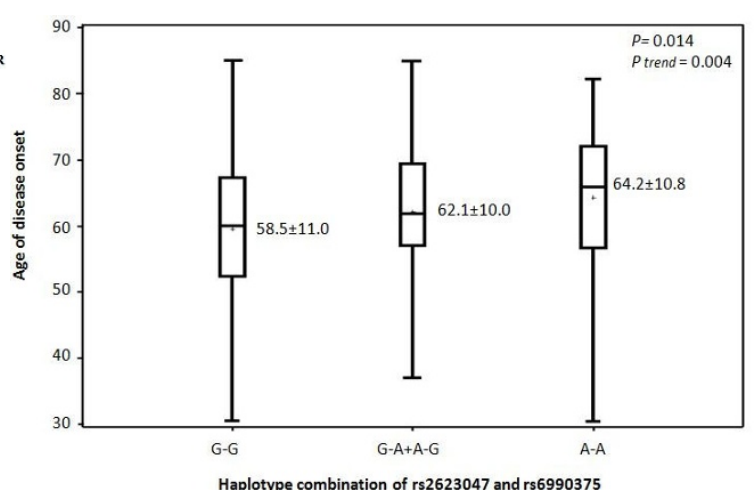

(B)

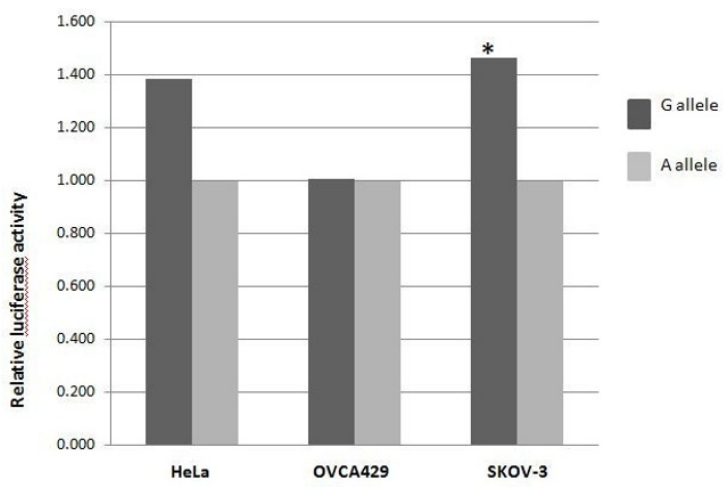

(D)

Figure 1 SULF1 SNP information, effects on age of disease onset, survival, and promoter activity. (A) The gene structure, SNP location, predicted functionality of SNPs, and electrophoresis gel pictures; (B) Haplotype combination of rs2623047 and rs6990375 and age of disease onset; G-G: rs2623047G-rs6990375G; G-A/A-G: rs2623047G-rs6990375A and rs2623047A-rs6990375G; A-A: rs2623047A-rs6990375A; (C) Progressionfree survival; rs2623047 AA vs. rs2623047 GG/GA; (D) HeLa, OVCA429, and SKOV-3 cell lines were co-transfected with the rs2623047 G, or rs2623047 A constructor plasmid and Renilla-TK plasmids. The relative luciferase activity was assessed with the Renilla luciferase activity. Each experiment was performed in triplicate. ${ }^{*} P<0.05$. 
$\mathrm{CO}_{2}$. The cultured cells were transiently transfected with $1.0 \mu \mathrm{g}$ of rs2623047 G or rs2623047 A reporter constructs, using the FuGENE HD kit (Roche Applied Science, IN). The p-TK renilla luciferase (pRL-TK) (Promega) construct was co-transfected as an internal control to evaluate experimental variation, such as transfection efficiency and cell viability. The luciferase activities were quantified by a Dual-Luciferase Reporter Assay System (Promega), and the relative luciferase activity was calculated as the ratio of firefly to renilla luciferase activity, according to the manufacturer's instructions. Each experiment was repeated three times.

\section{Statistical Analysis}

Statistical analysis was performed using the Chi-square test or analysis of variance (ANOVA) analysis for categorical variables and continuous variables, respectively. The Proc Allele procedure in the SAS/Genetics program (SAS Institute Inc., Cary, NC) was used to calculate linkage disequilibrium (LD). The Kaplan-Meier method and the log-rank test were used to estimate PFS and OS. The Cox proportional hazards regression model was used to analyze individual prognostic factors. All statistical tests were two-sided, a $P$ value of 0.05 was considered statistically significant, and all analyses were performed using the Statistical Analysis System/Genetics software (SAS version 9.13; SAS Institute Inc.)

\section{Results}

Demographic and clinicopathologic characteristics of the study population have been described elsewhere [18]. Since there are significant racial differences in allele distributions of some SULF1 SNPs and the majority of the patients with available DNA samples were non-Hispanic whites $(136 / 168,80.9 \%)$, we included non-Hispanic whites only in further analysis. As shown in Table 2 of clinicopathologic characteristics in this study, the mean age of disease onset and standard deviation (SD) was 61.8 \pm 10.7 years, and $12.5 \%$ were younger than 50 years. Among the 136 white patients, $91.9 \%$ had an advanced disease with 102 patients (75.6\%) diagnosed at stage III and 22 patients (16.3\%) diagnosed at stage IV. Most patients had high grade $(127,95.5 \%)$ and serous cell type $(109,80.2 \%)$, and 85 patients $(62.5 \%)$ had obtained optimal debulking during primary surgery.

Table 3 shows genotype distribution of the five SNPs. The LD analysis showed disequilibrium coefficient $\mathrm{D}^{\prime}=0.965$ and Correlation coefficient $r^{2}=0.872$ for rs6990375 G>A and rs3802278 G>A; D' $=0.981$ and $r^{2}=$ 0.678 for rs6990375 G>A and rs3087714 C $>\mathrm{T} ; \mathrm{D}^{\prime}=1.000$ and $r^{2}=0.919$ for rs3802278 G>A and rs3087714 $\mathrm{C}>\mathrm{T}$, but other pairs showed lower $\mathrm{D}^{\prime}$ and $r^{2}$ values, suggesting that rs6990375 G>A can capture the majority of rs3802278 G>A and rs3087714 $\mathrm{C}>\mathrm{T}$ changes in the $5^{\prime}$
Table 2 Demographic and clinicopathologic characteristics in non-Hispanic white ovarian cancer patients

\begin{tabular}{|c|c|c|}
\hline Characteristics & Number of patients & $\%$ \\
\hline Age at Diagnosis (years) & 136 & \\
\hline$<50$ & 17 & 12.5 \\
\hline $50-70$ & 86 & 63.2 \\
\hline$>70$ & 33 & 24.3 \\
\hline Surgical stage ${ }^{a}$ & 135 & \\
\hline I & 5 & 3.7 \\
\hline$\|$ & 6 & 4.4 \\
\hline III & 102 & 75.6 \\
\hline IV & 22 & 16.3 \\
\hline Tumor Grade ${ }^{a}$ & 133 & \\
\hline 1 & 6 & 4.5 \\
\hline 3 & 127 & 95.5 \\
\hline Histology & 136 & \\
\hline Serous & 109 & 80.2 \\
\hline Mucinous & 2 & 1.5 \\
\hline Endometrioid & 2 & 1.5 \\
\hline Clear cell & 1 & 0.7 \\
\hline Brenner & 3 & 2.2 \\
\hline Mixed & 19 & 14.0 \\
\hline
\end{tabular}

${ }^{a}$ Missing patient information: 1 for surgical stage; 3 for tumor grade.

UTR. When we stratified the age of disease onset by these genotypes, we found that all five SNPs were more or less associated with age of onset of ovarian cancer. For example, the rs $2623047 \mathrm{G}>\mathrm{A}$ showed an association with age of disease onset (Table 3); the patients with the AA genotype had a mean age of onset of $65.0 \pm 9.9$ years; and those with the AG genotype had $61.2 \pm 10.8$ years, while those with the rs2623047 GG showed $56.8 \pm 10.7$ year age of onset $(P=0.027$ for the ANOVA test). The trend test showed a $P$ value of 0.007 for a decreasing age with the $\mathrm{G}$ allele in a dose-dependent manner (Table 3). The rs13264163 AG heterozygotes also showed the youngest age of onset among all genotypes of rs13264163A $>$ G $(P=0.016)$ (Table 3$)$. We also found that the early age of disease onset was associated with the $\mathrm{G}$ allele of rs6990375 G>A [rs6990375 GG: $60.0 \pm$ 10.7 years; rs6990375 GA: $61.8 \pm 10.6$ years; rs6990375 AA: $69.1 \pm 9.0$ years $(P=0.013)]$ (Table 3$)$. As we noticed in the LD analysis, rs6990375 G>A had a $r^{2}>0.8$ with rs3802278 $\mathrm{G}>\mathrm{A}$ and rs3087714 $\mathrm{C}>\mathrm{T}$; therefore, we also observed the significant trends in differences of age of disease onset among genotypes of rs3802278 G>A and rs3087714 $\mathrm{C}>\mathrm{T}$ ( $P_{\text {trend }}=0.021$ and 0.041 , respectively), even though the differences were not significant in ANOVA tests $(P=0.069$ and 0.119$)$.

We further evaluated the combined allele effect on age of disease onset. Because rs2623047 G>A and rs6990375 G>A showed significant differences among genotypes 
Table 3 SULF1Genotype distribution and age of disease onset

\begin{tabular}{|c|c|c|c|}
\hline Genotypes & Number of patients (\%) & $\begin{array}{l}\text { Age at diagnosis } \\
\text { (years, mean } \pm S D)^{b}\end{array}$ & $P$-value \\
\hline $\mathrm{rs} 2623047 \mathrm{G}>\mathrm{A}^{\mathrm{a}}$ & & & 0.027 \\
\hline GG & $16(11.9)$ & $56.8 \pm 10.7$ & \\
\hline GA & $80(59.3)$ & $61.2 \pm 10.8$ & \\
\hline AA & $39(28.9)$ & $65.0 \pm 9.9$ & \\
\hline$G$ allele frequency & $112(41.5)$ & & $P_{\text {trend }}{ }^{c}=0.007$ \\
\hline A allele frequency & $158(58.5)$ & & \\
\hline rs13264163 A>G & & & 0.016 \\
\hline $\mathrm{AA}$ & $70(51.4)$ & $63.7 \pm 10.5$ & \\
\hline$A G$ & $53(39.0)$ & $58.6 \pm 10.5$ & \\
\hline GG & $13(9.6)$ & $64.9 \pm 10.6$ & \\
\hline A allele frequency & $193(71.0)$ & & $P_{\text {trend }}{ }^{c}=0.266$ \\
\hline $\mathrm{G}$ allele frequency & $79(29.0)$ & & \\
\hline rs6990375 G>A & & & 0.013 \\
\hline GG & $58(42.7)$ & $60.0 \pm 10.7$ & \\
\hline GA & $63(46.3)$ & $61.8 \pm 10.6$ & \\
\hline AA & $15(11.0)$ & $69.1 \pm 9.0$ & \\
\hline G allele frequency & $179(65.8)$ & & $P_{\text {trend }}{ }^{c}=0.009$ \\
\hline A allele frequency & $93(34.2)$ & & \\
\hline rs3802278 G>A & & & 0.069 \\
\hline GG & $59(43.4)$ & $59.7 \pm 11.4$ & \\
\hline GA & $65(47.8)$ & $62.8 \pm 10.0$ & \\
\hline $\mathrm{AA}$ & $12(8.8)$ & $66.7 \pm 9.5$ & \\
\hline$G$ allele frequency & $183(67.3)$ & & $P_{\text {trend }}{ }^{c}=0.021$ \\
\hline A allele frequency & $89(32.7)$ & & \\
\hline rs3087714 C>T & & & 0.119 \\
\hline $\mathrm{CC}$ & $63(46.3)$ & $60.1 \pm 11.3$ & \\
\hline$C T$ & $62(45.6)$ & $62.7 \pm 10.1$ & \\
\hline$\pi$ & $11(8.1)$ & $66.6 \pm 10.0$ & \\
\hline $\mathrm{C}$ allele frequency & $188(69.1)$ & & $P_{\text {trend }}{ }^{c}=0.041$ \\
\hline $\mathrm{T}$ allele frequency & $84(30.9)$ & & \\
\hline
\end{tabular}

a One sample failed in this genotype.

${ }^{b}$ One-way ANOVA (Analysis of variance) for age differences among 3 genotypes for each SNP.

${ }^{c} P$ values for the trend test of age at diagnosis among 3 genotypes for each SNP from a general linear model.

and significant trends, and rs6990375 G>A is in LD with rs3802278 G>A and rs3087714 C>T, we only included those two SNPs in the haplotype analysis. The significant differences in age of disease onset remained among carriers of the haplotype of rs2623047G and rs6990375G as compared with other haplotypes $(P=$ 0.014; $\left.P_{\text {trend }}=0.004\right)$ as shown in Figure 1B. In further analysis, we also found that $\mathrm{rs} 2623047 \mathrm{~A}>\mathrm{G}$ was associated with PFS. Patients with the G allele (i.e., the GG/ GA genotypes) showed a longer PFS than patients with the AA genotype $(28.3 \pm 2.6$ months vs. $11.7 \pm 2.0$ months; $P=0.016$ ) (Figure $1 C$ ), whereas this association with PFS was not observed for other SULF1 SNPs.

Since rs 2623047 is located in the putative promoter region of SULF1, we further tested its effect on the promoter activity. We constructed luciferase reporter plasmids with either rs2623047 G allele or rs2623047 A allele and transiently transfected them into three cancer cell lines, OVCA429, SKOV-3, and HeLa. We found that the SULF1 promoter containing rs2623047 G exhibited an increased luciferase activity, compared with the rs2623047 A in SKOV-3 and HeLa cell lines, but only SKOV-3 ovarian cancer cell lines showed a statistically significant difference $(P=0.028)$, whereas HeLa cells showed a marginal difference with a $P$ value of 0.058 (Figure 1D). Intriguingly, it is known that OVCA 429 forms tumor slowly and less aggressively in nude mice $[21,22]$, whereas SKOV-3 is highly tumorigenic [23], potentially relating to the differences in the promoter activity in the two lines.

\section{Discussion}

SULF1 is a recently identified heparin-degrading endosulfatase, which catalyzes the 6-O desulfation of HSPGs, 
co-receptors for heparin-binding growth factors and cytokine signaling pathways [12-14,24-27]. Moreover, SULF1 has been linked with a tumor suppression function and its expression was ubiquitous but reportedly downregulated in most of cancer cell lines [28]. The mRNA expression of SULF1 has been reported to inhibit tumor growth and angiogenesis in breast cancer cell lines [29] and also altered cisplatin-treatment response in ovarian cancer [15].

In this study, we genotyped five putatively functional common SULF1 SNPs to investigate associations between these genetic variants and clinical outcomes in ovarian cancer patients. We found that all five SNPs were more or less associated with age of onset of ovarian cancer, especially rs2623047 G>A and rs6990375 G>A. We also found that rs $2623047 \mathrm{G}$ allele was associated with a longer PFS in the ovarian cancer patients, suggesting that carriers of the rs $2623047 \mathrm{G}$ allele may be more responsive to treatment. Our luciferase reporter gene assay of rs2623047 G>A further showed that the G allele exhibited slightly higher promoter activity in SKOV-3 and HeLa cancer cell lines, which is consistent with one published study in which ovarian cancer patients with higher expression of SULF1 were more sensitive to platinum chemotherapy compared to others with lower SULF1 expression [15], suggesting that the $G$ allele had a tumor suppression effect. However, the biological relevance for an association between rs $2623047 \mathrm{G}$ allele and early onset of ovarian cancer remains unclear. It has been reported that multiple genetic or epigenetic changes are involved in signaling of certain growth factors leading to tumorigenesis [30-33], which may be potentially related to the SNP effects on the development of cancer. Although several studies reported that SULF1 expression was downregulated in different types of cancer [11-14], SULF1 was upregulated in gastric and pancreatic cancers $[24,34]$. A recent study also showed that SULF1 mRNA and protein expression were increased in the aging articular cartilage [35]. Therefore, our results call for additional replication studies with larger sample sizes and studies on possible mechanistic studies underlying the observed associations.

In the United States, epithelial cancer of the ovary is the fifth most common cause of death related to malignant conditions among women and the most leading cause of death from gynecologic malignancies [36]. Despite the fact that it is highly curable if diagnosed early, due to lack of symptoms in early stages of the disease, the majority of patients had presented with advanced diseases and subsequently had a worse prognosis. Unlike other cancers, there are no currently accepted standard screening tests to detect ovarian cancer at an early stage. More knowledge about ovarian cancer clinical characteristics will help develop more effective approaches to the disease. Hopefully in the future, our findings of the age difference by genetic variants could be a part of the efforts. However, our study had some limitations because of its small sample size. Additional studies with larger sample sizes with mechanistic studies to understand biological relevance of SULF1 SNPs in the development of ovarian cancer are needed to validate the role of SULF1 SNPs in age of disease onset and prognosis of ovarian cancer.

\section{Acknowledgements}

This research was supported in part by a National Institutes of Health Ovarian Specialized Programs of Research Excellence grant (P50 CA08363) to GBM, a BLANTON-DAVIS Ovarian Cancer Research Development Award to L-EW, grants from the National Cancer Institute (R01 CA131274 and R01 ES011740) to QW, and a Cancer Center Core grant from the National Cancer Institute to M. D. Anderson (CA016672). We thank Sarah H. Taylor at MD Anderson's Tumor Registry for help with the clinical data, Zhibin Hu and Kejing Xu for the laboratory assistance.

\section{Author details}

'Department of Epidemiology, The University of Texas M. D. Anderson Cancer Center, Houston, TX 77030, USA. ²Department of Gynecologic Oncology, The University of Texas M. D. Anderson Cancer Center, Houston, TX 77030, USA. ${ }^{3}$ Department of Systems Biology, The University of Texas M. D. Anderson Cancer Center, Houston, TX 77030, USA.

\section{Authors' contributions}

$\mathrm{CH}$ participated in the study design and conducted the laboratory experiments, performed the statistical analysis, prepared figures, and tables and drafted the manuscript. YH performed the luciferase assay experiment in cell lines and participated the analysis and manuscript preparation. KHL provided patients' samples and clinical information. ZL advised on designing primers and helped laboratory experiments. GBM supported the study, provided information on the study design and edited the manuscript. QW advised on study design, and revised the manuscript preparation, and supported the study. L-EW participated in the study design, oversaw the entirety of the project and assisted in the analysis and the manuscript preparation. All authors read and approved the manuscript.

\section{Competing interests}

The authors declare that they have no competing interests.

Received: 8 November 2010 Accepted: 7 January 2011

Published: 7 January 2011

\section{References}

1. Morimoto-Tomita M, Uchimura K, Werb Z, Hemmerich S, Rosen SD: Cloning and characterization of two extracellular heparin-degrading endosulfatases in mice and humans. J Biol Chem 2002, 277:49175-49185.

2. Ai X, Do AT, Lozynska O, Kusche-Gullberg M, Lindahl U, Emerson CP Jr: QSulf1 remodels the 6-O sulfation states of cell surface heparan sulfate proteoglycans to promote Wnt signaling. J Cell Biol 2003, 162:341-351.

3. Bernfield M, Gotte M, Park PW, Reizes O, Fitzgerald ML, Lincecum J, Zako M: Functions of cell surface heparan sulfate proteoglycans. Annu Rev Biochem 1999, 68:729-777.

4. Liu D, Shriver Z, Qi Y, Venkataraman G, Sasisekharan R: Dynamic regulation of tumor growth and metastasis by heparan sulfate glycosaminoglycans. Semin Thromb Hemost 2002, 28:67-78.

5. Pye DA, Vives RR, Hyde P, Gallagher JT: Regulation of FGF-1 mitogenic activity by heparan sulfate oligosaccharides is dependent on specific structural features: differential requirements for the modulation of FGF-1 and FGF-2. Glycobiology 2000, 10:1183-1192.

6. Filmus J: Glypicans in growth control and cancer. Glycobiology 2001, 11:19R-23R 
7. Folkman J: Angiogenesis-dependent diseases. Semin Oncol 2001, 28:536-542.

8. Iozzo RV, San Antonio JD: Heparan sulfate proteoglycans: heavy hitters in the angiogenesis arena. J Clin Invest 2001, 108:349-355.

9. Xiang YY, Ladeda V, Filmus J: Glypican-3 expression is silenced in human breast cancer. Oncogene 2001, 20:7408-7412.

10. Dhoot GK, Gustafsson MK, Ai X, Sun W, Standiford DM, Emerson CP Jr: Regulation of Wnt signaling and embryo patterning by an extracellular sulfatase. Science 2001, 293:1663-1666.

11. Abiatari I, Kleeff J, Li J, Felix K, Buchler MW, Friess H: Hsulf-1 regulates growth and invasion of pancreatic cancer cells. J Clin Pathol 2006, 59:1052-1058

12. Lai J, Chien J, Staub J, Avula R, Greene EL, Matthews TA, Smith DI, Kaufmann SH, Roberts LR, Shridhar V: Loss of HSulf-1 up-regulates heparin-binding growth factor signaling in cancer. J Biol Chem 2003, 278:23107-23117.

13. Lai JP, Chien J, Strome SE, Staub J, Montoya DP, Greene EL, Smith DI, Roberts LR, Shridhar V: HSulf-1 modulates HGF-mediated tumor cell invasion and signaling in head and neck squamous carcinoma. Oncogene 2004, 23:1439-1447.

14. Lai JP, Chien JR, Moser DR, Staub JK, Aderca I, Montoya DP, Matthews TA, Nagorney DM, Cunningham JM, Smith Dl, et al: hSulf1 Sulfatase promotes apoptosis of hepatocellular cancer cells by decreasing heparin-binding growth factor signaling. Gastroenterology 2004, 126:231-248.

15. Staub J, Chien J, Pan Y, Qian X, Narita K, Aletti G, Scheerer M, Roberts LR, Molina J, Shridhar V: Epigenetic silencing of HSulf-1 in ovarian cancer: implications in chemoresistance. Oncogene 2007, 26:4969-4978.

16. Johnson $A D$, Wang $D$, Sadee $W$ : Polymorphisms affecting gene regulation and mRNA processing: broad implications for pharmacogenetics. Pharmacol Ther 2005, 106:19-38.

17. Johnson AD, Zhang Y, Papp AC, Pinsonneault JK, Lim JE, Saffen D, Dai Z, Wang $D$, Sadee W: Polymorphisms affecting gene transcription and mRNA processing in pharmacogenetic candidate genes: detection through allelic expression imbalance in human target tissues. Pharmacogenet Genomics 2008, 18:781-791.

18. Han CH, Wei Q, Lu KK, Liu Z, Mills GB, Wang LE: Polymorphisms in the survivin promoter are associated with age of onset of ovarian cancer. Int J Clin Exp Med 2009, 2:289-299.

19. Ozols RF, Bundy BN, Greer BE, Fowler JM, Clarke-Pearson D, Burger RA, Mannel RS, DeGeest K, Hartenbach EM, Baergen R: Phase III trial of carboplatin and paclitaxel compared with cisplatin and paclitaxel in patients with optimally resected stage III ovarian cancer: a Gynecologic Oncology Group study. J Clin Oncol 2003, 21:3194-3200.

20. Therasse P, Arbuck SG, Eisenhauer EA, Wanders J, Kaplan RS, Rubinstein L, Verweij J, Van Glabbeke M, van Oosterom AT, Christian MC, Gwyther SG: New guidelines to evaluate the response to treatment in solid tumors. European Organization for Research and Treatment of Cancer, National Cancer Institute of the United States, National Cancer Institute of Canada. J Natl Cancer Inst 2000, 92:205-216.

21. Lee LF, Hellendall RP, Wang Y, Haskill JS, Mukaida N, Matsushima K, Ting JP: IL-8 reduced tumorigenicity of human ovarian cancer in vivo due to neutrophil infiltration. J Immunol 2000, 164:2769-2775.

22. Shaw TJ, Senterman MK, Dawson K, Crane CA, Vanderhyden BC: Characterization of intraperitoneal, orthotopic, and metastatic xenograft models of human ovarian cancer. Mol Ther 2004, 10:1032-1042.

23. Cao Q, Abeysinghe $\mathrm{H}$, Chow O, Xu J, Kaung H, Fong C, Keng P, Insel RA, Lee WM, Barrett JC, Wang N: Suppression of tumorigenicity in human ovarian carcinoma cell line SKOV-3 by microcell-mediated transfer of chromosome 11. Cancer Genet Cytogenet 2001, 129:131-137.

24. Li J, Kleeff J, Abiatari I, Kayed H, Giese NA, Felix K, Giese T, Buchler MW, Friess H: Enhanced levels of Hsulf-1 interfere with heparin-binding growth factor signaling in pancreatic cancer. Mol Cancer 2005, 4:14.

25. Nawroth R, van Zante A, Cervantes S, McManus M, Hebrok M, Rosen SD: Extracellular sulfatases, elements of the Wnt signaling pathway, positively regulate growth and tumorigenicity of human pancreatic cancer cells. PLoS One 2007, 2:e392.

26. Jayson GC, Lyon M, Paraskeva C, Turnbull JE, Deakin JA, Gallagher JT: Heparan sulfate undergoes specific structural changes during the progression from human colon adenoma to carcinoma in vitro. $J$ Biol Chem 1998, 273:51-57.
27. Lai JP, Thompson JR, Sandhu DS, Roberts LR: Heparin-degrading sulfatases in hepatocellular carcinoma: roles in pathogenesis and therapy targets. Future Oncol 2008, 4:803-814.

28. Lai JP, Sandhu DS, Shire AM, Roberts LR: The tumor suppressor function of human sulfatase 1 (SULF1) in carcinogenesis. J Gastrointest Cancer 2008, 39:149-158.

29. Narita K, Staub J, Chien J, Meyer K, Bauer M, Friedl A, Ramakrishnan S, Shridhar V: HSulf-1 inhibits angiogenesis and tumorigenesis in vivo. Cancer Res 2006, 66:6025-6032.

30. Dudek H, Datta SR, Franke TF, Birnbaum MJ, Yao R, Cooper GM, Segal RA, Kaplan DR, Greenberg ME: Regulation of neuronal survival by the serinethreonine protein kinase Akt. Science 1997, 275:661-665.

31. Gibson S, Tu S, Oyer R, Anderson SM, Johnson GL: Epidermal growth factor protects epithelial cells against Fas-induced apoptosis. Requirement for Akt activation. J Biol Chem 1999, 274:17612-17618.

32. Koury MJ, Bondurant MC: Erythropoietin retards DNA breakdown and prevents programmed death in erythroid progenitor cells. Science 1990, 248:378-381.

33. Hanahan D, Weinberg RA: The hallmarks of cancer. Cell 2000, 100:57-70.

34. Junnila S, Kokkola A, Mizuguchi T, Hirata K, Karjalainen-Lindsberg ML, Puolakkainen P, Monni O: Gene expression analysis identifies overexpression of CXCL1, SPARC, SPP1, and SULF1 in gastric cancer. Genes Chromosomes Cancer 2009, 49:28-39.

35. Otsuki S, Taniguchi N, Grogan SP, D'Lima D, Kinoshita M, Lotz M: Expression of novel extracellular sulfatases Sulf- 1 and Sulf-2 in normal and osteoarthritic articular cartilage. Arthritis Res Ther 2008, 10:R61.

36. Jemal A, Siegel R, Ward E, Hao Y, Xu J, Murray T, Thun MJ: Cancer statistics, 2008. CA Cancer J Clin 2008, 58:71-96.

doi:10.1186/1756-9966-30-5

Cite this article as: Han et al.: Polymorphisms in the SULF1 gene are associated with early age of onset and survival of ovarian cancer. Journal of Experimental \& Clinical Cancer Research 2011 30:5.

\section{Submit your next manuscript to BioMed Central and take full advantage of:}

- Convenient online submission

- Thorough peer review

- No space constraints or color figure charges

- Immediate publication on acceptance

- Inclusion in PubMed, CAS, Scopus and Google Scholar

- Research which is freely available for redistribution

Submit your manuscript at www.biomedcentral.com/submit
Ciomed Central 